\title{
Article
}

\section{Community pharmacist perceptions of delivering post-hospital discharge Medicines Use Reviews for elderly patients}

Rutter, Paul, Ramsbottom, Helen and Fitzpatrick, Ray

Available at http://clok.uclan.ac.uk/16494/

Rutter, Paul ORCID: 0000-0003-4106-1515, Ramsbottom, Helen and Fitzpatrick, Ray (2017) Community pharmacist perceptions of delivering posthospital discharge Medicines Use Reviews for elderly patients. International Journal of Clinical Pharmacy, 39 (1). pp. 3-36. ISSN 2210-7703

It is advisable to refer to the publisher's version if you intend to cite from the work. http://dx.doi.org/10.1007/s11096-016-0400-8

For more information about UCLan's research in this area go to http://www.uclan.ac.uk/researchgroups/ and search for <name of research Group>.

For information about Research generally at UCLan please go to http://www.uclan.ac.uk/research/

All outputs in CLoK are protected by Intellectual Property Rights law, including Copyright law. Copyright, IPR and Moral Rights for the works on this site are retained by the individual authors and/or other copyright owners. Terms and conditions for use of this material are defined in the policies page.

\section{CLoK}

Central Lancashire online Knowledge www.clok.uclan.ac.uk

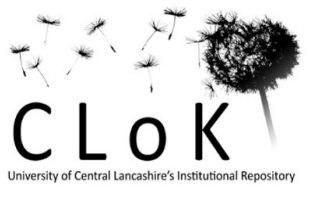




\section{Community pharmacist perceptions of delivering post-hospital discharge Medicines Use Reviews for elderly patients}

\section{Introduction}

When patients transfer between care settings, the risk of miscommunication and unintended changes to medicines is a significant problem [1]. Incomplete documentation of changes in medication for older patients on discharge has been linked to preventable readmissions [2]. In the UK, a nationally contracted service known as Medicines Use Reviews (MUR) is offered by community pharmacists to address any problems patients have with their medicines [3]. Since 2011, the MUR service has targeted specific patient groups, identified as being at particular risk of medication related problems or poor adherence, and includes those patients recently discharged from hospital [3]. Early evidence suggests uptake of post discharge MURs (dMURs) has been poor [4].

In 2012, a Department of Health steering group recommended that formal communication channels between hospital and community pharmacy should be established so that dMURs become an integral part of the medicines pathway [5]. In light of the documented problems that occur with medication on transfer of care of elderly patients, a randomised controlled feasibility study (the 'Medicines Support Study') was devised to explore the effect a hospital referral system to patients' regular community pharmacist had on their care. This paper reports on a small part of the ongoing evaluation of the study.

\section{Aim}

To evaluate the perspective of community pharmacists on the usefulness of dMUR referrals from the hospital, the suitability of the patients referred and their overall views on the service.

\section{Ethical Approval}


Ethics approval for the study was obtained from the Northwest Research Ethics Committee (Ref 13/NW/0779).

\section{Method}

All pharmacists working on medical wards at Southport and Ormskirk NHS Trust, identified hospital in-patients aged over 65 years who, in their professional opinion, could potentially benefit from a dMUR with their regular community pharmacist. Patients were left written information about the study by the ward pharmacist, who then contacted the researcher (HR) via email or leaving patient contact details in an agreed location within the pharmacy department. HR would normally visit the patient within 24 hours of this initial recruitment screen to assess fully patient eligibility for recruitment to the study. Inclusion and exclusion criteria were largely dictated by the NHS England service specifications for MUR and the practicalities of delivering the service and have previously been reported $[3,6]$.

The researcher approached eligible patients to discuss involvement in the study and provide a further information leaflet describing the dMUR service and study follow-up. Consenting patients were randomised to be referred for dMUR at their regular community pharmacy or standard hospital discharge care. Referrals included details of medicines stopped, started and changed during admission, with reasons and suggested follow-up, drug allergies, a contact telephone number for the patient and a complete list of discharge medication.

To gauge community pharmacist opinion of the referrals sent by the hospital a self-completed survey was distributed. Questionnaire survey was chosen in preference to focus group or interview as opinions from as many community pharmacists as possible was wanted. Questions were developed from a similar questionnaire previously sent to hospital pharmacists who were involved in identifying potential patients for dMUR referral as part of this study, and from the recent evaluation of the Wales Discharge Medicines Review service [7]. The survey consisted of a mix of open, closed and Likert [5 point agreement scale] 
questions to specifically address the referrals sent by the hospital and the community pharmacists' opinion of the service.

Prior to survey distribution, all pharmacies who had a dMUR referral from the hospital were contacted to confirm that the pharmacist who had received the referral was still working from those premises. Following verbal consent, surveys were sent by fax or email. Surveys could be returned by fax, email or post. Follow-up phone calls to non-responders were made at 2 and 4 weeks to prompt return of the survey. Quantitative data was analysed descriptively using Excel and open-ended questions themed.

\section{Results}

During the 9-month study, 30 patients were referred, via fax, to their regular community pharmacist for a dMUR. Twenty-five community pharmacists were sent referrals; some were sent more than one. A total of $20 \mathrm{dMURs}$ were carried out ( $66.7 \%$ completion rate). Reasons given for non-completion, included patients being unable to attend the pharmacy $(n=4)$, patients were non-contactable $(n=1)$ or the pharmacist had not received the referral $(n=1)$.

Twenty-one pharmacists were traced after the 9-month study and nineteen returned a completed questionnaire $(90.4 \%$ response rate). Seven $(36.8 \%)$ of these worked for independent pharmacies, nine (47.4\%) for multiples and three $(15.8 \%)$ for supermarket pharmacies. Fourteen (73.7\%) reported conducting at least one dMUR following referral from the hospital.

There were four instances (21\%) where pharmacists felt they had received insufficient information to enable them to conduct a full dMUR. They did not elaborate on the reasons for this. However, when asked in general what further information they would like to receive, reasons for medication changes made in hospital $(n=5,26.3 \%)$ and the specific indications for new medicines ( $n=4,21 \%)$ were most commonly reported, with one respondent requiring further patient contact details. 
Concerns were raised regarding aspects of the referrals received. Seven pharmacists $(36.8 \%)$ felt that it was hard to engage patients in having the dMURs, citing examples such as such as 'patient non-attendance' or the 'need to get special permission to conduct an MUR at home' when the patient was unable to attend the pharmacy. Eight respondents $(42.1 \%)$ viewed dMURs as 'more complex' than other types of MUR, with $40 \%(n=6 / 15)$ reporting a dMUR to take between 20 and 39 minutes.

All respondents agreed that dMURs would help patients to manage their medicines better after being in hospital and that adherence problems $(n=19,100 \%)$ and medication errors $(n=17$, 90\%) would be identified and resolved sooner than they otherwise would be. Pharmacists saw value in the service with free text comments such as the dMUR referral service was excellent' or 'useful' and 'not enough patients were referred' or that they 'would love to have more involvement'.

Eight pharmacists (42\%) had performed dMURs during the study period that were not direct referrals as part of the service. Most $(n=7 / 8,88 \%)$ had reported undertaking between 1 and 5 , although one pharmacist stated they had done more than twenty.

\section{Discussion}

This report is timely in the context of a recently published systematic review of studies evaluating the role of community pharmacists in the transition of patients from secondary to primary care [8]. In this study, community pharmacists held positive opinions of the dMUR service and could see the benefit to patients regarding identification of medicine nonadherence and avoidance of medicine errors. These positive attitudes mirror those of hospital pharmacists who were also involved in the study [9].

However, running the current service posed challenges to community pharmacists. Around a third of community pharmacists felt that it was hard to engage patients in having dMURs and was exemplified by patients not attending or being unable to attend appointments (e.g. 
housebound patients). The uncertainty of older patients in their ability to leave home to attend a dMUR in the early post discharge period, exacerbated by a lack of perceived benefit, was also a barrier in the initial recruitment of patients to the referral service [6]. Indeed the intention was to screen out such patients at the recruitment stage. The patients reported by community pharmacists as unwilling or unable to attend where therefore patients who had previously specified that they would be able to do so. This issue is therefore likely to be much larger than that encountered by the community pharmacists in this study. Secondly, contractual, legal and regulatory restrictions placed on community pharmacists hinder MUR provision; community pharmacists are required to apply to NHS England each time they wish to conduct an MUR in the patient's own home. UK regulations allow the 'responsible pharmacist' to be off premises 2 hours per day but in practice many core activities (eg handing out prescriptions) require the pharmacist to be physically present at the pharmacy. These constraints were reflected in our study, in that only $10 \%$ of community pharmacists were able to offer domiciliary visits.

An alternative of a telephone MUR was considered as part of the study protocol but discounted as a patient and public involvement group raised concerns over telephone dMURs for older patients due to risk of mishearing/misinterpretation of information and a mistrust of discussing as complex and personal a subject as medication over the telephone.

Pharmacists wanted more patients referred (with a fuller data set) but reported performing few dMURs outside this study. The fact that very few dMURs were conducted outside of the study reflects previous reports, whereby dMUR activity is low in the absence of formal referral systems [4]. Recurring barriers in the literature are difficulty identifying patients and lack of information from secondary care. This reinforces the need to develop robust referral systems from hospital to community pharmacy. It has been suggested that using an electronic referral systems may overcome these difficulties [4]. Such a system has been developed in East Lancashire (England), but outcome data and user feedback from these systems are awaited. 
Some pharmacists in this study perceived greater complexity in performing dMURs compared to a 'standard' MUR. It is known that transitions of care are associated with a high numbers of medication changes, which may be confusing for patients and professionals alike $[1,2]$. Therefore it might be expected that reviews involving these patients would be perceived as more complicated, and also result in a longer length of time needed to perform a dMUR. This was not observed; reported times in this study were similar to those reported for 'standard' MURs [10]. It may be possible that the referrals made from this study provided a focus for the dMUR and allowed the pharmacist to spend less time 'fact finding' with patients, although this is unsubstantiated.

The major limitation of this work is the small-scale nature of the study involving one hospital and the associated community pharmacists. The same study, but scaled, to include more hospitals that capture a wider geographical area is needed. This would allow us to tackle some of the problems encountered in this study, such as minimising patients lost to follow-up and building in the ability for pharmacists to perform dMURs off site.

\section{Conclusion}

This study shows that referral of elderly patients to community pharmacy is well received by community pharmacies and is feasible. The study highlights the need for improved communication between the hospital and community pharmacies and a pressing need to overcome the barrier of performing dMURs other than in the confines of a community pharmacy in this patient group.

Conflicts of Interest: None 


\section{References}

1. Coleman EA, Smith JD, Raha D, Min S-. Post hospital medication discrepancies:

Prevalence and contributing factors. Arch Intern Med. 2005;165(16):1842-1847.

2. Witherington EMA, Pirzada OM, Avery AJ. Communication gaps and readmissions to hospital for patients aged 75 years and older: Observational study. Qual Saf Health Care. $2008 ; 17(1): 71-75$.

3. Pharmaceutical Services Negotiating Committee/NHS Employers. Medicines Use Review and Prescription Intervention Service Specification. London: PSNC and NHS Employers. 2013.

4. Royal Pharmaceutical Society Innovator's Forum. Hospital referral to community pharmacy: An innovator's toolkit to support the NHS in England. London: RPS. 2014.

5. Steering Group on Improving the Use of Medicines (for better outcomes and reduced waste). Improving the use of medicines for better outcomes and reduced waste - An action plan. London: Dept of Health. 2012.

6. Ramsbottom H F, Fitzpatrick R, Rutter P. Post Discharge Medicines Use Review (dMUR) Service for Older Patients: Recruitment issues in a feasibility study. Int $\mathrm{J}$ Clin Pharm. 2016;38:208-212

7. Alam MF, Blenkinsopp A, Cohen D, Davies $\mathrm{P}$, Hodson $\mathrm{K}$ et al, eds. Evaluation of the Discharge Medicines Review Service. [Report submitted to Community Pharmacy Wales] Wales: Universities of Cardiff, Bradford and South Wales, 2014.

8. Nazar H, Nazar Z, Portlock J, Todd A, Slight SP. A systematic review of the role of community pharmacies in improving the transition from secondary to primary care. $\mathrm{Br} \mathrm{J}$ Clin Pharmacol 2015 November;80(5):936-948 
9. Ramsbottom H, Rutter P, Fitzpatrick R. A questionnaire survey of hospital pharmacists' views on recruiting older patients to a post discharge medicines use review (dMUR) service. Int J Pharm Pract. 2016;24(Supp1):39

10. Blenkinsopp A, Bond C, Celino G, Inch J, Gray N. National evaluation of the new community pharmacy contract. 2009. London. Pharmacy Practice Research Trust. ISBN 9780955696985 